\section{Art therapy: an underutilized, yet effective tool}

\author{
Robert A. Bitonte, 1 Marisa De Santo² \\ 1Department of Physical Medicine and \\ Rehabilitation, University of California, \\ Irvine Medical Center, Orange, CA; \\ zUniversity of California, Irvine, CA, USA
}

\section{Abstract}

Art therapy has been recognized as beneficial and effective since first described by Adrian Hill in 1942. Even before this time, art therapy was utilized for moral reinforcement and psychoanalysis. Art therapy aids patients with, but not limited to, chronic illness, physical challenges, and cancer in both pediatric and adult scenarios. Although effective in patient care, the practice of art therapy is extremely underutilized, especially in suburban areas. While conducting our own study in northeastern Ohio, USA, we found that only one out of the five inpatient institutions in the suburban area of Mahoning County, Ohio, that we contacted provided continuous art therapy to it's patients. In the metropolitan area of Cuyahoga County, Ohio, only eight of the twenty-two inpatient institutions in the area provided art therapy. There could be many reasons as to why art therapy is not frequently used in these areas, and medical institutions in general. The cause of this could be the amount of research done on the practice. Although difficult to conduct formal research on such a broad field, the American Art Therapy Association has succeeded in doing such, with studies showing improvement of the patient groups emotionally and mentally in many case types.

\section{Early works}

Art is known as one of the earliest forms of communication, dating back to the cave art of the Paleolithic age. ${ }^{1}$ Art therapy has been increasingly recognized as beneficial and effective in the treatment of various types of both mental and physical conditions. For example, art therapy has shown to be effective as a treatment for traumatic brain injury, schizophrenia, sexual abuse, breast cancer, post-traumatic stress disorder, as well as numerous other conditions. ${ }^{2-6}$

This has been described and studied since Adrian Hill's published work in 1942. Art therapy has been shown to be effective in a broad range of conditions. It has been generally recognized that art therapy enhances communication, and bolsters self-esteem. Despite the apparent effectiveness of art therapy, and its ready acceptance by patients, the prevalence of the utilization of art therapy was this studies' inquiry. Despite ongoing and recent studies showing art therapy to be beneficial, it's utilization appears to be underutilized for reasons unknown at this time.

Adrian Hill is generally known as the first person to use the term Art Therapy in 1942. Many of his works of art are displayed in the Imperial War Museum in London, works that he painted from the front lines as an official war artist during World War I. Hill personally discovered the therapeutic quality of art making when he was recovering from tuberculosis himself in 1938, and recorded his ideas in 1945 in Art versus Illness. ${ }^{6}$ He was employed as the first official art therapist in 1946 by the Netherene, a state psychiatric hospital in the United Kingdom. He later became the president of the British Association of Art Therapists. Hill's contributions became a milestone for the acceptance and practice of what we know today as art therapy.

\section{More developed practices}

Art therapy is not specific in it's practices, making it customizable to the ever-changing life of a patient. Adolescents who experience abuse, low self-esteem, depression, or any other psychological issues tend to withdraw from their parental figures, which works against traditional verbal therapy. Art therapy is a way for these troubled adolescents to feel expressive in a non-judgmental environment. ${ }^{7}$ Art therapy is also increasingly important with children and adolescents facing chronic illness. These practices are used to enhance the young patient's emotional, physical, and cognitive development. A very important example is within the field of pediatric oncology, where restoring self image for the patient is crucial to continue battling their illness. Furthermore, art therapy can provide some end-of-life care for patients to create mementos for their family before death, to help cope, and say goodbye. ${ }^{6}$ These same principles are applicable to adults as well. In adult oncology, art therapy has been used to help survivors create a life outside of cancer, helping these individuals find their identity past their survivor label. ${ }^{6}$ Art therapy in the healthcare setting has also been used in adult cases of hemodialysis, HIV/AIDS, Alzheimer's, and traumatic brain injury. In addition, adults with schizophrenia, bipolar disorder, borderline personality disorder, PTSD, trauma from sexual abuse, dementia, and many other conditions can find lasting benefits from art therapy. ${ }^{8}$ Again, although it may be difficult to quantify the effectiveness of art therapy, studies have repeatedly shown that art therapy is beneficial to patients within a broad spectrum of conditions.
Correspondence: Marisa De Santo, 34102 Blue Lantern, Dana Point, CA 92629, USA.

E-mail: mdesanto7@gmail.com

Key words: art, therapy, mental illness, head trauma.

Contributions: the authors contributed equally.

Conflict of interests: the authors declare no potential conflict of interests.

Received for publication: 14 February 2014.

Accepted for publication: 14 February 2014.

This work is licensed under a Creative Commons Attribution NonCommercial 3.0 License (CC BYNC 3.0).

(C) Copyright R.A. Bitonte and M. De Santo, 2014 Licensee PAGEPress, Italy

Mental Illness 2014; 6:5354

doi:10.4081/mi.2014.5354

\section{Specific applications}

\section{Traumatic brain injury}

In a pilot study addressing group art therapy for patients with traumatic brain injury, six subjects with traumatic brain injury between the ages of 24 and 71 participated in five one hour art therapy sessions. The subjects were evaluated before and after the study using the Depression Anxiety and Stress Scales. Throughout the sessions, the subjects participated in low-anxiety activities like making collages and working with 3D figures. After the study was completed, 4 of 6 subjects had a decrease in depression, 3 of 6 had a decrease in anxiety, and 5 of 6 had a decrease in stress. ${ }^{2}$

\section{Schizophrenia}

Several studies have been produced to show the effectiveness of art therapy for schizophrenics. An interesting example is an 83-year-old male schizophrenic who was not responding to medications, and was reported by caretakers to have very unusual behaviors. A psychiatrist initiated art therapy practices with him, having him depict parts of his life through drawing. The patient's verbal resistance began to disappear and the patient's progress was able to be documented. ${ }^{3}$

\section{Sexual abuse}

In a four-year follow up of a pilot study, it was shown that for sexually abused children and adolescents, art therapy, paired with cognitive behavioral therapy, was an effective intervention to reduce symptoms that are commonly associated with childhood sexual abuse. ${ }^{4}$

\section{Epilepsy in children and adoles- cents}

In a focus group with children with epilepsy, the use of art enabled said children and adoles- 


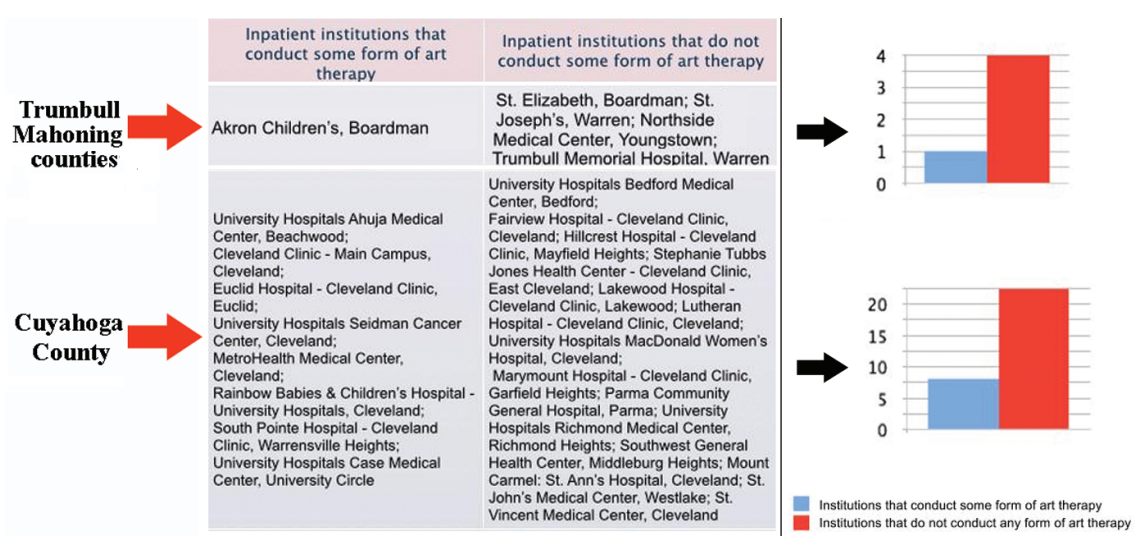

Figure 1. Institutions that conduct and do not conduct at therapy in Trumbull and Mahoning Counties versus Cuyahoga County.

cents to express repressed emotions related to their illness. With the finding that many of the children in the focus group had never met another adolescent afflicted with epilepsy, the focus group served as an extremely valuable outlet for these children and adolescents during critical times in their lives. The art work produced was able to record their growth along the way, resulting in the participants feeling self discovery and can be believed to aid in an increase of social activity outside of the focus group, rather than social isolation that can become common in these cases. ${ }^{6}$

\section{Acute stress disorder}

In an intervention with a 48-year-old woman who had injured a motorcyclist three weeks prior in a car accident, the treatment seeked to lower her overwhelming anxiety, sleep problems, heart palpitations, and excessive flashbacks of the accident. With certain drawing techniques and manipulation of various mediums, and discussion of such in relation to her experience with the art therapist, the client was able to rearrange the sensory and cognitive overexcitation, and thus feel a sense of control over the traumatic experience. ${ }^{6}$

\section{Study interest and design}

The first author's interest in the treatment of traumatic brain injury, and the second author's interest in art, were the impetus of interest for this study. Studied were two areas in Ohio. An urban area Cuyahoga County (which includes Metropolitan Cleveland), and a more rural suburban Trumbull and Mahoning counties were examined. The inquiry was to determine the availability of art therapy services in both if these rural and urban atmospheres in Northeast Ohio, in the midwest section of the Unites States. The survey was personally conducted by the second author by phone. Each listed inpatient psychiatric unit was successfully contacted.

\section{Results}

Our study found that in urban Cuyahoga County, only 8 of 22 (36\%) inpatient facilities utilize art therapy as a treatment modality. In Trumbull and Mahoning counties, 1 of 5 (20\%) inpatient institutions offered and utilized art therapy (Figure 1). Contrary to expectations, we believed the practice of art therapy would be much higher in urban areas, and our study concluded that this is not necessarily true. We attempted to clarify why art therapy was not used in the non-utilizing-institutions. The questionnaire included the response options of i) lack of instructors; ii) lack of interest or demand by staff or patients; iii) lack of support personnel or administration; or iv) lack of funding. This study was unable to locate persons qualified to answer this inquiry and has been left for further study.

\section{Conclusions}

Our concluding thoughts on this study is that art therapy, although having the ability to be beneficial to various patient populations, is underutilized for unknown reasons at this time. The underutilization of art therapy must be studied and understood before progress can be made. Advocacy can then be tailored to remedy the precise reason for underutilization of art therapy.

\section{References}

1. Roberts J.M. The new penguin history of the new world. London: Penguin Books; 2007. pp 23-26.

2. Graves G. Group art therapy for patients with traumatic brain injuries: a pilot study. Degree Diss.; Virginia Commonwealth University, Richmond, Virginia; 2006.

3. Morrow R. The use of art therapy in a patient with chronic schizophrenia. Jefferson Journal of Psychiatry. 1985. Available from: http://jdc.jefferson.edu/cgi/ viewcontent.cgi? article $=1084 \&$ context $=$ je ffjpsychiatry

4. Pifalo T. Art therapy with sexually abused children and adolescents: extended research study. Art Therapy 2006;23:181-5.

5. Chang F. From emptiness to energizing body. In: Malchiodi CA, ed. Art therapy and health care. New York: The Guilford Press; 2013. p 154.

6. Malchiodi CA. Art therapy and health care. New York: Guilford Press; 2013.

7. Riley S. Art therapy with adolescents. Western J Med 2013;175:54-7.

8. Rivera RA. Art therapy for individuals with severe mental illness. Masters Diss.; University of Southern California, Los Angeles, USA; 2008. 